\title{
ANTIBACTERIAL ACTIVITY OF AQUEOUS EXTRACT OF GARLIC (ALLIUM SATIVUM) ON STANDARD STRAINS
}

\author{
Gaurav Saxena ${ }^{1}$, Kalpana Sadawarte ${ }^{2}$, Navinchandra M. Kaore ${ }^{3}$
}

${ }_{1}^{1}$ Assistant Professor, Department of Microbiology, Government Medical College, Ratlam, Madhya Pradesh.

2Professor and HOD, Department of Microbiology, People's College of Medical Sciences and Research Centre, Bhopal, Madhya Pradesh. 3 Professor and HOD, Department of Microbiology, Raipur Institute of Medical Sciences, Raipur, Chhattisgarh.

\section{ABSTRACT}

\section{BACKGROUND}

Many plants are known for their medicinal properties. Plant derived compounds are a potential source of natural antimicrobial agents. But this potential is largely unused till today. As antimicrobial resistance is increasing day by day, search for nov el and safe antimicrobial agents is the need of the hour. Garlic is one such potential source of such agents. It is a common dietary ingredient and also known for its medicinal value from centuries. This study was undertaken to assess the antimicrobial activity of crude ex tract of garlic on standard strains Escherichia coli (ATCC 25922), Staphylococcus aureus (ATCC 25923) and Pseudomonas aeruginosa (ATCC 27853).

\section{MATERIAL AND METHODS}

The crude extract was prepared by maceration of $50 \mathrm{~g}$ of shade dried garlic cloves in $100 \mathrm{~mL}$ of distilled water for $24 \mathrm{hrs}$. The filtrate was used as crude extract for preparation of discs of various concentrations ranging from 714 to $89 \mathrm{mg} / \mathrm{mL}$ and was used to test antimicrobial activity by Kirby Bauer disc diffusion method along with positive control and negative control.

\section{RESULTS}

Crude aqueous garlic extract was found to be active against standard strains of Escherichia coli, Staphylococcus aureus at concentration range of 714 to $178 \mathrm{mg} / \mathrm{mL}$ and there was no activity against standard strain of Pseudomonas aeruginosa even at $714 \mathrm{mg} / \mathrm{mL}$ concentration.

\section{CONCLUSIONS}

Garlic has some antimicrobial compounds, which are active against both Gram-positive and Gram-negative bacteria. These compounds, if extracted have the potential to emerge as effective antimicrobial agents in future.

\section{KEY WORDS}

Garlic, Alliin, Allicin, Antibacterial Activity, Escherichia Coli, Staphylococcus Aureus and Pseudomonas Aeruginosa.

HOW TO CITE THIS ARTICLE: Saxena G, Sadawarte K, Kaore NM. Antibacterial activity of aqueous extract of garlic (allium sativum) on standard strains. J. Evolution Med. Dent. Sci. 2018;7(19):2320-2322, DOI: 10.14260/jemds/2018/523

\begin{abstract}
BACKGROUND
Garlic (Allium sativum) is a common dietary ingredient and also known for its medicinal value from centuries. It has potential antihyperlipidaemic, antihypertensive, antithrombotic, expectorant, antioxidant, anti-inflammatory and antimicrobial properties.[1,2,3,4,5]

The antimicrobial effect of garlic is attributed primarily to organosulfur compounds, such as allicin,[6,7] ajoene[8] and diallyl sulphides. ${ }^{[9]}$ However, others have demonstrated that the contribution of antimicrobial properties is also from phenolic compounds.[10] Alliin (oxygenated sulphur amino acid) was found to be the stable precursor that is converted to Allicin- a thiosulfinate (<+>-S-methyl-L-cysteine sulfoxide) by the action of an enzyme alliinase, which is also present in cloves.
\end{abstract}

'Financial or Other Competing Interest': None.

Submission 23-12-2015, Peer Review 05-02-2016,

Acceptance 12-02-2016, Published 07-05-2018.

Corresponding Author:

Dr. Kalpana Sadawarte,

Professor and HOD

Department of Microbiology,

People's College of Medical Sciences and

Research Centre, Bhanpur - 462037,

Bhopal, Madhya Pradesh.

E-mail: drkalpanasadawarte@gmail.com

DOI: $10.14260 /$ jemds $/ 2018 / 523$
The transformation of alliin into the biologically active allicin molecule occurs only upon crushing the cloves and is extremely rapid, being complete in seconds.[6]

Inhibition of certain thiol-containing enzymes (Alcohol dehydrogenase, thioredoxin reductase, RNA polymerase) in the microorganisms by the rapid reaction of thiosulfinates with thiol groups is supposed to be the main mechanism involved in the antibiotic effect.[6] Due to the increasing resistance to currently available antibiotics, there is urgent need to search for newer synthetic and natural compounds active against such microorganisms. Plant extracts are the natural and potential source of such compounds.

Present study was undertaken to assess the antibacterial activity of crude aqueous garlic extract on standard bacterial strains.

\section{MATERIAL AND METHODS \\ Preparation of aqueous garlic extract}

Fresh garlic bulbs were purchased from local market (Bhopal, India). Garlic cloves were then peeled and washed with sterile distilled water and then allowed to shade dry; $50 \mathrm{~g}$ of dried garlic cloves were then transferred to laboratory grinder and grinded to coarse powdered form. This powder was then transferred to a sterile conical flask ( $250 \mathrm{~mL}$ capacity) and $100 \mathrm{~mL}$ of sterile distilled water was poured into the flask and thoroughly mixed with a sterile spatula. The conical flask was 
then covered with sterile aluminium foil and mixture was allowed to macerate for 24 hours at room temperature.

Next day, the mixture was first filtered using bi-layered sterile muslin cloth and subsequently by Whatman filter paper no. 1. Resultant $70 \mathrm{~mL}$ filtrate (On account of losses during filtration) was considered containing $50 \mathrm{~g}$ of garlic extract in $70 \mathrm{~mL}$ distilled water $(714 \mathrm{mg} / \mathrm{mL})$ of crude extract. This crude aqueous extract was used for sensitivity testing.

\section{Antibacterial Sensitivity Testing using Kirby Bauer Disc Diffusion Technique}

Doubling dilutions of crude aqueous extract $(714 \mathrm{mg} / \mathrm{mL})$ was prepared in distilled water, i.e. $357 \mathrm{mg} / \mathrm{mL}, 178 \mathrm{mg} / \mathrm{mL}$, $89 \mathrm{mg} / \mathrm{mL}$.

Sterile disc $(6 \mathrm{~mm})$ was procured from HiMedia, Mumbai. These were used for preparation of disc of various dilutions of crude aqueous extract using $10 \mu \mathrm{L}$ of each dilution.

Antibiotic susceptibility testing is done by Kirby Bauer disc diffusion method on Mueller Hinton Agar (MHA) on three standard strains of Staphylococcus aureus (ATCC 25923), Escherichia coli (ATCC 25922) and Pseudomonas aeruginosa (ATCC 27853).[11]

All three standard strains were first inoculated in test tubes containing $2 \mathrm{~mL}$ of peptone water and kept in incubator at $37^{\circ} \mathrm{C}$ for 4 hours. Turbidity of the each broth was matched to 0.5 McFarland using Densimat (bioMerieux, France). A lawn culture was then done from this broth using sterile cotton swab on $90 \mathrm{~mm}$ Mueller Hinton's Agar (MHA) plate.

One disc of each dilution of extract and positive control (Gentamycin disc $(10 \mu \mathrm{g})$ for Staphylococcus aureus and Colistin disc $(10 \mu \mathrm{g})$ for Escherichia coli and Pseudomonas aeruginosa) and negative control (10 $\mu \mathrm{L}$ of distilled water on sterile disc) was placed over each MHA plate.

Each plate was incubated for 18 hours at $37^{\circ} \mathrm{C}$ after which activity on each plate was assessed by measuring the zone of inhibition around each disc.

For testing stability of the extract at $100^{\circ} \mathrm{C}$ it was free steamed for 20 minutes and then allowed to cool. Antibacterial activity of this extract was tested as above.

\section{RESULTS}

In the present study, different concentrations of the crude aqueous garlic extract was tested for their activity on three standard strains by Kirby Bauer disc diffusion technique.

Extract was active against Staphylococcus aureus and Escherichia coli at concentration range of 714 to $178 \mathrm{mg} / \mathrm{mL}$, while there was no activity against Pseudomonas aeruginosa at any concentration (Table 1, Figure 1, 2, 3).

\begin{tabular}{|c|c|c|c|c|c|c|}
\hline & \multicolumn{7}{|c|}{ Zone Size (In mm) } \\
\hline Organism & NC & PC & $\begin{array}{c}\mathbf{7 1 4} \\
\mathbf{m g} / \mathbf{m L}\end{array}$ & $\begin{array}{c}\mathbf{3 5 7} \\
\mathbf{m g} / \mathbf{m L}\end{array}$ & $\begin{array}{c}\mathbf{1 7 8} \\
\mathbf{m g} / \mathbf{m L}\end{array}$ & $\begin{array}{c}\mathbf{8 9} \\
\mathbf{m g} / \mathbf{m L}\end{array}$ \\
\hline $\begin{array}{c}\text { Staphylococcus } \\
\text { aureus (ATCC } \\
25823)\end{array}$ & - & 23 & 22 & 18 & 12 & - \\
\hline $\begin{array}{c}\text { Escherichia } \\
\text { coli (ATCC } \\
\text { 25822) }\end{array}$ & - & 16 & 18 & 14 & 10 & - \\
\hline $\begin{array}{c}\text { Pseudomonas } \\
\text { aeruginosa } \\
\text { (ATCC 27853) }\end{array}$ & - & 14 & 12 & - & - & - \\
\hline \multicolumn{7}{|c|}{ Table 1: Antibacterial activity of crude garlic extract at } \\
various concentrations \\
\hline
\end{tabular}

Also we found that after free steaming for 20 minutes, there was no zone of inhibition against any strain.

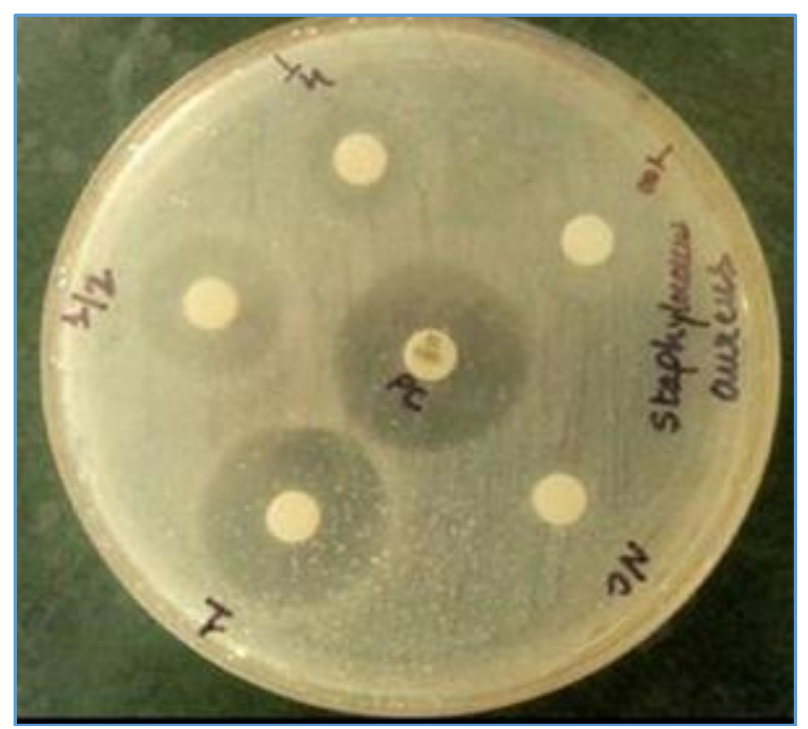

Figure 1. Activity of Aqueous Garlic Extract on Staphylococcus Aureus

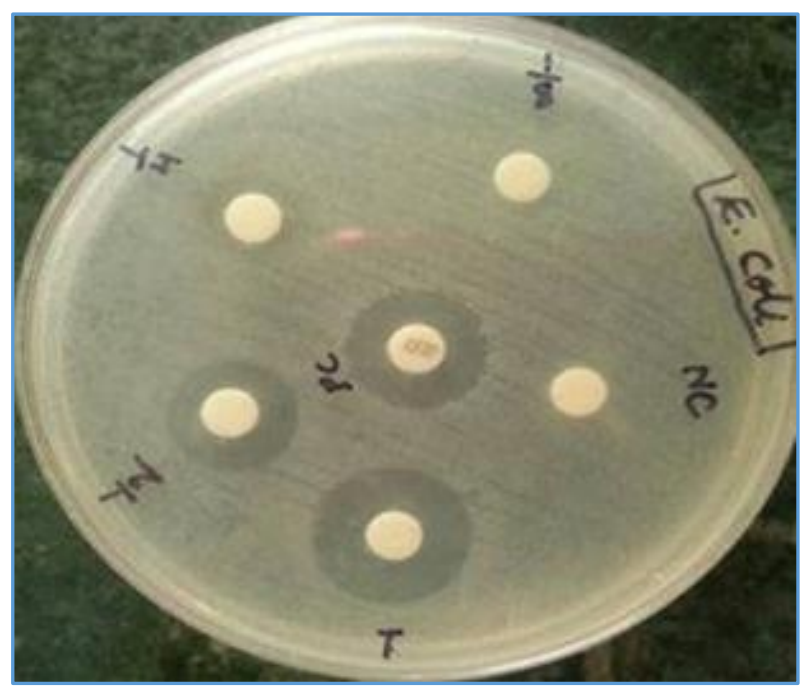

Figure 2. Activity of Aqueous Garlic Extract on Escherichia Coli

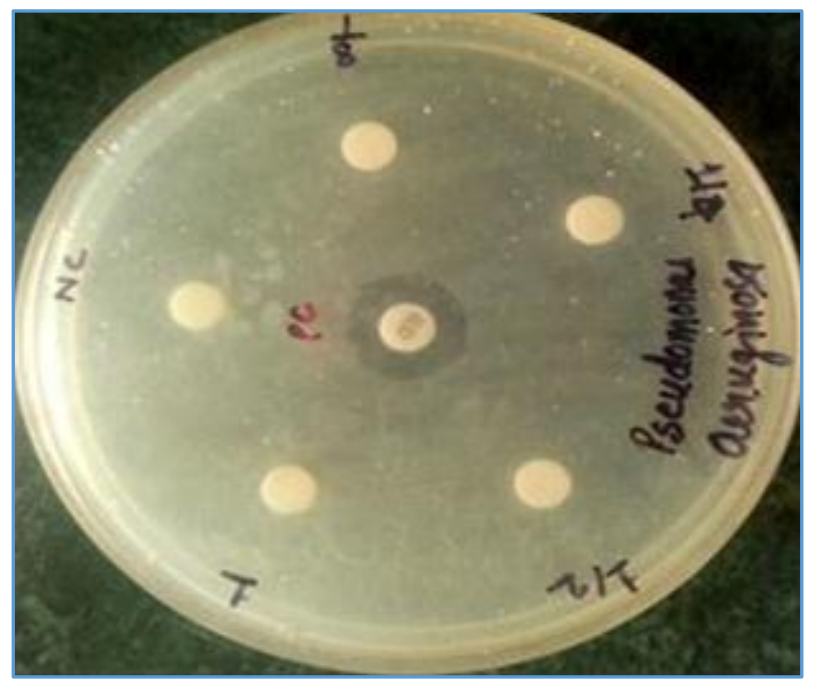

Figure 3. Activity of aqueous garlic extract on pseudomonas aeruginosa 


\section{DISCUSSION}

The extract showed concentration dependent antibacterial activity against Staphylococcus aureus, Escherichia coli, but no activity against Pseudomonas aeruginosa.

At $714 \mathrm{mg} / \mathrm{mL}$ concentration, maximum zone of inhibition was observed against Staphylococcus aureus and no zone of inhibition was observed against Pseudomonas aeruginosa. This shows that extract was more active against Gram-positive bacteria than Gram-negative bacteria.

Similar findings for Staphylococcus aureus was also reported by Deresse $D,[12]$ but they reported the activity in concentration of $15 \mathrm{mg} / \mathrm{mL}$. Activity at higher concentration in our study may be because of shade drying of garlic cloves and then converting them into powdered form which may account for some loss of activity.

In our study, we have not found any activity of aqueous garlic extract against Pseudomonas aeruginosa. This was in contrast to study done by Kumar S, et al.[13] This might be because of concentrated extract used by them without dilution. Extract might be active against Pseudomonas aeruginosa probably at higher concentration.

This antibacterial action of garlic may be due to organosulfur compounds, such as allicin, ajoene and diallyl sulphides as proposed by various researchers. $[6,7,8,9]$

Activity of extract was lost after free steaming for 20 minutes. This shows that active antibacterial compounds of garlic were heat sensitive and this is in accordance with the study done by Deresse D.[12] who reported that activity of aqueous extract was lost by autoclaving at $121^{\circ} \mathrm{C}$ for 15 minutes.

This study shows that some antibacterial substances were present in garlic which if extracted in pure form can pave the path for formulation of new antimicrobial agent. This is just a preliminary study and testing of this extract should be done on large number of clinical isolates and on resistant strains such as MRSA, VRSA, ESBL, etc. before moving on to more refined procedures for extraction of active compounds from garlic.

\section{CONCLUSION}

Garlic extract has some antimicrobial compound that is active against Staphylococcus aureus and Escherichia coli. This active ingredient is heat labile.

We propose that active compound of garlic, if extracted can be used topically for treatment of burn and other wound infections and also possibly by other routes for treatment of various other infections.

This study concludes that plant-based antimicrobial agents can be safe and effective alternative for treating variety of infections. Detailed research on such medicinal plants can pave way to counter antibiotic resistance.

\section{REFERENCES}

[1] Lu X, Rasco BA, Jabal JM, et al. Investigating antibacterial effects of garlic (Allium sativum) concentrate and garlicderived organosulfur compounds on campylobacter jejuni by using Fourier transform infrared spectroscopy, Raman spectroscopy and electron microscopy. Appl Environ Microbiol 2011;77(15):5257-69.

[2] Harris JC, Cottrell SL, Plummer S, et al. Antimicrobial properties of allium sativum (garlic). Appl Microbiol Biotechnol 2001;57(3):282-6.

[3] Kumar M, Berwal JS. Sensitivity of food pathogens to garlic (allium sativum). J Appl Microbiol 1998;84(2):213-5.

[4] Gardner CD, Messina M, Lawson LD. Soy, garlic and ginkgo biloba: their potential role in cardiovascular disease prevention and treatment. Curr Atheroscler Rep 2003;5(6):468-75.

[5] Yeh YY, Liu L. Cholesterol-lowering effect of garlic extracts and organosulfur compounds: human and animal studies. J Nutr 2001;131(3S):989s-93s.

[6] Ankri S, Mirelman D. Antimicrobial properties of allicin from garlic. Microbes Infect 1999;1(2):125-9.

[7] Cavallito CJ, Bailey JH. Allicin, the antibacterial principle of allium sativum. I. Isolation, physical properties and antibacterial action. J Am Chem Soc 1944;66(11):1950-1.

[8] Naganawa R, Iwata N, Ishikawa K, et al. Inhibition of microbial growth by ajoene, a sulfur-containing compound derived from garlic. Appl Environ Microbiol 1996;62(11):4238-42.

[9] Ross ZM, O'Gara EA, Hill DJ, et al. Antimicrobial properties of garlic oil against human enteric bacteria: evaluation of methodologies and comparisons with garlic oil sulfides and garlic powder. Appl Environ Microbiol 2001;67(1):475-80.

[10] Benkeblia N. Antimicrobial activity of essential oil extracts of various onions (allium cepa) and garlic (allium sativum). LWT Food Science and Technology 2004;37(2):263-8.

[11] Clinical and laboratory standards institute. Performance standards for antimicrobial susceptibility testing; twenty-third informational supplement. CLSI document M100-S23, Pennsylvania, USA 2013.

[12] Deresse D. Antibacterial effect of garlic (allium sativum) on staphylococcus aureus: an in vitro study. Asian Journal of Medical Sciences 2010;2(2):62-5.

[13] Kumar S, Nancy M, Singh D, et al. Evaluating the antibacterial activity of plant extracts against bacterial pathogens. Journal of Drug Delivery and Therapeutics 2012;2(4):182-5. 